\title{
Tourist-Host Interactions and Tourism Experiences: A Study of Tourism Experiences and Effects in Sikles, Nepal
}

\author{
Prakash Upadhyay \\ Department of Anthropology, Prithvi Narayan Campus, Pokhara, Tribhuvan University, Nepal \\ prak-socio@hotmail.com
}

Article History

Received 26 March 2019

Accepted 25 August 2019

Keywords

Commercialized

hospitality,

anthropological

response, brand

ambassador, hitch
Corresponding Editor

Ramesh Raj Kunwar

kunwar.dr@gmail.com
Abstract

It is necessary to create a positive interaction between host and tourist for achieving and maintaining sustainable tourism in a destination. The quality and frequency of interaction between tourist and resident contributes to tourists' experience, perception of the visited destination, local socio-cultural and environmental status, and acceptance and tolerance of tourists by residents. The key objective of this study is to examine the international tourist experiences, interaction with residents, and the social, cultural and environmental effects of tourism in the host community of Sikles. The research was conducted among 50 international tourist visiting Sikles during January, 2019. The results shows that village tourism of Sikles is a phenomenon representing nature conservation, adventure, life style, experience and above all benefit to the local people. Foreign tourist visited Sikles for adventure-trekking, relaxes and rest and their expectations were fulfilled during their visit, and there prevails a jovial relationship between tourist and host with a broad spectrum of tourism experiences and impact on local community. However, tourism as a global phenomenon has brought both positive and negative impacts 
on economic, environmental and social lives which are crucial for leading changes and revitalization of local society, culture and economy of Sikles. Indigenous Gurung culture has become more differentiated and the forces of tourism are strong enough to influence every spheres of local life. But, the effervescent interaction between tourist and host, experiences, perspicacity of jovial relations, the budding social, cultural and environmental challenges has amplified the awareness of both tourist and host for sustainable eco-friendly tourism.

\section{Prelude}

The most noteworthy point in economic dimension of tourism is interconnection between tourism and economic development. Tourism has been achieved as an alternative policy to aid economic growth. Other than approaching tourism sector as a tool for development of the whole economy of or country, it brings economic benefits for the settlements; since tourism includes may subsector from transportation to entertainment; from shopping to accommodation (Mill and Morrison, 1985). Can and Guner (2000), state that from supplier side, it is a sector and economic activity that occurs from the consumption and traveling activities of the visitors in one place. From another angle, tourism as a social event establishes relations between societies that have different social and cultural features; and creates interaction between different cultures, customs, and manners. Tourism may give rise to changes in social structure, patterns of behavior, and life styles. Cohen (1996) defines tourism through sociological perspectives: Firstly, tourism is a type of commercialized hospitality, which means tourism commercialize and eventually industrialize and institutionalize traditional guest-host relations. Secondly, modern mass tourism is a democratized expansion of aristocratic travel of an earlier age. Thirdly, tourism is a type of modern leisure activity free of obligations. Fourthly, Tourism is modern variety of pilgrimage travels in traditional societies. Fifth, tourism is an expression of basic cultural themes. Also, tourism is an acculturative process between tourists and host. Furthermore, tourism is an ethnic relation between tourist and host in terms of production of ethnic arts for tourism market, and commercializing of ethnic identities for tourists. Lastly, tourism is a form of neocolonialism as tourism creates a dependency between tourist sender metropolitan, developed, core countries and tourist receiver peripheral countries, on the global economic scale.

Burns (2004) states that other than consideration and conceptualization of tourism through social and cultural dimensions, there are also some sociological and anthropological impacts of tourism. One important source of sociological and anthropological impacts is the relation and interaction between tourist and host. Tourists interact with local residents during their stay in destination. For Ahmad (1986) tourism in itself is a cultural event. Interests of people on other cultures are main purpose of some tourism activity, and in any tourism activity, there is also a 
cultural interaction between comer and host. Cultural impact of tourism activity results from substantial cultural differences between residents and tourist, related to value and logic systems, religious beliefs, traditions, life-styles, customs, behavioral patterns, dressing codes, senses, attitudes, and so on. According to Berger (1978) cultural differences can create frustrated situations and misunderstanding in communication between residents and tourists. Furthermore, dwindling interests of tourists in host culture can reason reawakening and renewing of cultural heritage to sell it as a commodity in tourism sector. Being commodity process, cultural heritage may help to preserve the heritage, such as historical architecture, and artifacts. In opposition, it may create environmental impacts, degeneration and erosion in traditions, and beliefs (Cohen, 1979).

In Nepal since 1970's there has been a substantial growth of tourism. It not only generates income but also assist to raise direct employment in all segments-hotel industry, trekking, mountaineering etc. In seasonal character, trouble-free relationship between tourist and local people, job opportunities, and tourism impact may be a path to open the door of development for many beautiful places. Hostguest interactions are an inevitable occurrence while on holiday, and tourists can assume their interaction with the host community will result in positive experiences. However, when tourists encounter negative experiences, conflicting attitudes may arise towards the local community, and potentially the destination may face both positive and negative social-cultural and environmental impacts. Bowen and Schouten (2008) argue that the tourism experience involves tourist interaction with service personnel, other tourists and a wider host society, which is said to take place within the sectors and sub-sectors that constitute tourism space along with the impacts of tourism services. Murphy, Pritchard, and Smith (1999) described the sectors of tourism space as the destination environments and service infrastructure. Murphy et al. (1999) noted that tourists desire particular experiences from the setting itself, as well as from the service infrastructure that supports their visit. Tourists' interactions with the different sub-sectors should be satisfactory in order for tourists to achieve an overall sense of quality with the tourism experience. Pizam, Neumann, and Reichel (1978) describe tourist satisfaction as a collection of tourists' attitudes about specific domains in the vacation experience. Satisfaction with the tourism experience has been linked to tourists' expectations about a destination's tourism product (Graefe and Vaske, 1987; Murphy et al., 1999; Pizam, et al. 1978; Weiermair, 2000). When expectations are not met, the difference between perceived reality and expectations can lead to dissatisfaction, negative attitude formation, and a decreased sense of quality with the tourism experience (Weiermair, 2000). Quality in tourism, as defined by the World Tourism Organization (UNWTO) is: The satisfaction of all the legitimate product and service needs, requirements and expectations of the consumer, 
at an acceptable price, in conformity with the underlying quality determinants such as safety and security, hygiene, accessibility, transparency, authenticity and harmony of the tourism activity concerned with its human and natural environment (as cited in Jonsson Kvist and Klefsjo, 2006).

Hosts' acceptance and tolerance of tourists is vital for a successful tourism industry, and is one of the major factors contributing to tourists' sense of quality with the tourism experience (Thyne, Lawson, and Todd, 2004). Thyne et al. (2004) elaborate by suggesting hosts' attitudes towards tourists can influence tourists' attitudes about returning to a destination or recommending it to others. Therefore, attitudes and experiences of tourists are highly important, as a negative tourist experience can restrict growth in tourism and cause a decline in popularity of a destination (Getz, 1983). For Kozak (2006) negative behavior is the leading cause for dissatisfaction and complaints, and is the most frequently identified negative experience conveyed by tourists (De Albuquerque and McElroy, 2001). Knox (2004) stated that the tourist may have his vacation spoiled or enhanced by the resident; the resident may have his daily life enriched or degraded by the unending flow of tourists. Hence, host-guest interactions affect both quality of the tourism experience for tourists and quality of life for local communities. The latter has been considered widely in terms of resident attitudes towards tourism to understand quality of life for local communities, but few studies have focused on the opposite side of this social interaction. By taking this viewpoint, this current research is focused on tourists and host attitudes towards each other to help understand the quality of the tourism experience. This is important to know because tourist satisfaction is profoundly dependent on the host community, and a negative experience may result in negative attitudes towards not only the hosts, but also to the destination where the indigenous social-cultural structure and environment may be badly influenced. Various researches have revealed the impact of tourism on the host community and have delineated economic, environmental and socio-cultural costs and benefits. The majority of travel and tourism research works address the issue of the impacts of tourism as an important component which needs to be taken into consideration by decision makers involved in tourism planning (Gee, Mackens and Choy, 1989; Gunn, 1988; McIntosh and Goldener, 1990; Murphy, 1985). DeKadt (1979) points out the general failure of tourism destination planners to establish a clear framework to determine which questions need to be considered, and what factors should enter into their decision making. Similarly, Matheison and Wall (1982) present a synthesis of the research on the impacts of tourism which focuses on interrelationships of a combination of phenomena associated with tourism development.

Studies of the economic impacts of tourism have been commonly viewed as a positive force perhaps because of the ease of factual data collection involved which 
increases total income for the local economy, foreign currency earnings for the host country, direct and indirect employment, and tax revenues as well as stimulating secondary economic growth (Uysal, Pomeroy, and Potts, 1992; Peppelenbosh and Templeman, 1989; Bryant and Morrison, 1980; DeKadt, 1979; McNicoll, 1979). A large number of social and cultural impact studies consider tourism as a cultural exploiter or polluter (Young, 1977; Greenwood, 1989; Fanon, 1966). Additionally, tourism has frequently been criticized for the disruption of traditional social structures and behavioural patterns (Kousis, 1989, Butler, 1974). However, tourism has also been viewed as a means of revitalizing cultures when dying customs are rejuvenated for tourists (Witt, 1991; McKean, 1977; Boissevain, 1977). Studies of the environmental impact of tourism focus on tourism development, stress and preservation (Farrell and Runyan, 1991). Mountain region, alpine areas, coastlines, islands, lakes and habitat areas are generally sensitive to intense usage resulting from tourism development (Murphy, 1985). Krippendor (1982) urges planners to protect the resource on which tourism is dependent.

Saveriades (2001) stated that the social and cultural impacts of tourism on a host country have been a subject of increasing concern to social scientists and planners all over the world. Research in the field of resident's perceptions and attitudes on the social impact of tourism conducted over the last many decades consider tourism as a disruptor of traditional social structures and behavioural patterns. Furthermore, tourism seems to be blamed for all the ill fates of contemporary societies. However, the research of resident perceptions of the impact of tourism has been mainly descriptive with the base knowledge about resident attitudes coming from the analysis of quantitative surveys, which ask respondents to specify a level of agreement with positive or negative statements about the impact of tourism. To a large extent, all studies come to broadly similar conclusions, which actually leave the impact of tourism blurred. For getting most out of tourism industry, it requires a deep understanding of the visitor's patterns, perceptions, their experiences with local community, their motivations etc. The need of proper evaluation of the tourist -host relationship and the socio-cultural and environmental effects of tourism in destination is necessary to understand the extent of sustainable tourism drive led by Nepal. As the elements that effect resident reaction to tourists and tourism development are dynamic and complex in nature this research seeks a different way from the norm to add to the knowledge concerning rudiments that shape attitudes towards tourism held within the host community. This study explores the various elements that effect host community resident attitudes towards tourism. Specifically, the question this research seeks to answer is: 'How do tourist and resident interaction, experience and discernment of the relations, along with social, cultural and environmental impacts of tourism affect their support for tourism?' This will provide a basis for 
the improved management of tourists for environmental and other developmental goals. Given this, the key objective of this study is to examine international tourists' experiences, interaction with residents, and the social, cultural and environmental effects of tourism in the host community of Sikles. The fundamental premise is to understand what factors shape the overall tourism experience, especially from the social interaction perspective.

\section{Data and methods}

Located in the Madi Gaupalika (Rural Municipality) of Kaski district and one of the largest Gurung villages in Nepal, Sikles is the study site because this village is well known for domestic and international tourism and flow of tourist frequency is increasing. Both primary and secondary data were used in this study. Primary data was congregated from the fieldwork carried out in January 2019. In the period of January 2019 only 70 international tourists visited Sikles. As tourists do not accumulate in a particular area in the required time so random sampling method was espoused to collect the data from the 50 international tourists that were available during the data collection period. Semi-structured interview schedule was used to collect information on tourist details and their experiences, and in the process 50 visitors (28 Male and 22 Female) were interviewed. The tourists were observed while they arrived in Sikles on their way to their trekking destination and their interaction with local people in the hotels, the behavior of local people toward tourists and the interaction mode. The social, cultural and environmental effects of tourist inflow were also observed. Six key informants- 3 from Ama Samuha (mother's group) of Sikles and 3 representatives from hotel entrepreneurs were selected in order to collect views regarding the tourists' inflow and its effects on the host community. The key informants were selected on the principles that most members of any society do not know the full repertory of forms, meanings and functions of their culture as claimed by Sjoberg and Nett (1968). As such, key informants, as a result of their personal skills and position within the local society, are able to provide in-depth information and a deeper insight into what was going on around them.

\section{Tourism history and experiences in Sikles}

The Annapurna Region is one of the most notable tourist destinations, especially for trekking tourists. The region lies in the north-western part of Nepal. Popularly known as the Annapurna Trekking route comprising some of the world's highest peaks of above 8,000 m. and the world's deepest valley, the Kali Gandaki Valley; it has attracted trekkers from many countries (Banskota \& Sharma 1998). Nestled in lofty hills and mountains in the central Himalayan landscape of ACA (Annapurna Conservation Area established in 1986), Sikles (one of the largest Gurung villages in Nepal) is heavily gifted with tourism resources such as natural virginity, cultural 
diversity and piousness. Sikles is an indigenous Gurung village quite lucrative for village tourism. Thapa (2004) stated that Nepal's rural settings provide a strong foundation to promote rural and/or village-based tourism because of its unique lifestyle, unspoiled culture and tradition. The unspoiled Gurung culture and intact rural traditions of Sikles seemed to be a strong foundation to village tourism. If marketed in an innovative way it can bring tourism benefits in the villages that are off the main trekking trails and help create off-farm employment. Few other residents of the village are the Dalits from occupational caste community.

The tourism history of Sikles is related to the arrival of outsiders for bartering business many decades ago. Brahmin and Chhetrifrom their nearbyvillages settlements come to Sikles with the seeds of local potatoes, soyabeans and Gunri (bamboo mats). For Brahmin and Chhetri community people from nearby villages, the pilgrimage of Dudhpokhari during Janaipurnima and Maudukyufui (a pilgrimages site) in the period of Maghesakranti was the major attractions of Sikles. Later the arrival of western tourists begins after the inception of circuit Trekking Route and Eco Tourism Development Project (CTREDP) which is widely known as Ghalekharkha Sikles Eco Tourism Project (GSEP) established in 1992, taken as a first eco-tourism model project in Nepal for natural resources conservation and promotion of responsible tourism. This project was designed to develop a circuit trekking route in the lower belt of ACA where Sikles is one of the important destinations along this route. Natural conservation is one of the most important components of this region which includes the activities like forest nurseries operation and afforestation. Local infrastructure development as well as the awareness creation toward the environment is other component of the project which include construction of school, bridge, community toilet, drinking water schemes cleanup campaign, rubbish management pits format and informal education focusing to tourism and environment in the school. Sikles itself being a largest Gurung settlement along the eco trek route became successful to attract the tourism from its unique settlement and culture.

As a natural paradise, Sikles is surrounded by hills such as Parche Dada, Kori Dada, and Taprang Dada which cast colors across the horizon. Around 700 homes make up Sikles known as Cheuli (flat pastures) in Gurung language. Stone walkways lead from house to house, and chickens bustle up and down uneven staircases throughout the village. Wood, as primary source for fuel and heat, is piled alongside paths and outside of homes. Owing to the unique natural and socio-cultural beauty, tourists from all over the world visit Sikles. According to Nepal Tourism Statistics 2018 seasonality exists in tourist arrivals. The highest number of arrival is observed in November followed by March and there is no major change in sex and age group of tourist arrivals. The number of sampled foreign tourist visiting Sikles during January 2019 is depicted in table 1. 
Table 1: Tourists by country of origin

\begin{tabular}{|l|c|c|}
\hline \multicolumn{1}{|c|}{ Country } & Number of Tourists & Percent (\%) \\
\hline Australia & 1 & 2.0 \\
\hline China & 5 & 10.0 \\
\hline Holland & 3 & 6.0 \\
\hline British & 10 & 20.0 \\
\hline Israel & 2 & 4.0 \\
\hline Italy & 3 & 6.0 \\
\hline Singapore & 2 & 4.0 \\
\hline Slovakia & 2 & 4.0 \\
\hline Spain & 3 & 6.0 \\
\hline Switzerland & 7 & 14.0 \\
\hline USA & 10 & 20.0 \\
\hline Canada & 1 & 2.0 \\
\hline France & 1 & 2.0 \\
\hline Total & 50 & 100.0 \\
\hline
\end{tabular}

Source: Field Study, 2019

Among the 50 tourist interviewed, 20 percent were from Britain and United States respectively, followed by 14 percent Swiss, Chinese 10 percent and the rest from Australia, France, Holland, Israel, Italy, Singapore, Slovakia, Spain etc. Of these, 56 percent of tourists were male and the remaining 44 percent were female. It is envisaged that this could be because tourists usually come in pairs with their girl friend or spouse.

More than one fourth tourists were from 36-45 years old which denotes that mainly middle age tourists from developed countries are more active in travelling abroad.

Table 2: Tourists age group

\begin{tabular}{|c|c|c|}
\hline Age Group & Number of Respondents & Percent (\%) \\
\hline $16-25$ & 4 & 8.0 \\
\hline $26-35$ & 13 & 26.0 \\
\hline $36-45$ & 17 & 34.0 \\
\hline $46-60$ & 12 & 24.0 \\
\hline $60+$ & 4 & 8.0 \\
\hline Total & 50 & 100.0 \\
\hline
\end{tabular}

Source: Field Study, 2019 


\section{Travel partner}

Tourist needs company during their visit to new place. Table 3 illustrates the number of tourists who travelled through travel agency and those who travelled on their own. Majority of tourists travelled on their own.

Table 3: Travel partner

\begin{tabular}{|l|c|c|}
\hline \multicolumn{1}{|c|}{ Travel Partner } & Number of Respondents & Percent (\%) \\
\hline $\begin{array}{l}\text { On their own with family members/ } \\
\text { friends }\end{array}$ & 31 & 62.0 \\
\hline Through Travel Agency in group & 19 & 38.0 \\
\hline Total & 50 & 100.0 \\
\hline
\end{tabular}

Source: Field Study, 2019

A large number of tourists i.e. 62 percent travelled on their own with family members or friends. And the remaining 38 percent travelled through travel agency in group. This reveals that a large number of visitors to Sikles come on their own which may be because of self recreation and more freedom of travelling with their own people. The tourists arriving through travel agency were accompanied by Nepali guides.

\section{Length of stay and visit frequency to Sikles}

There is a close relationship between the image of a destination and duration of stay (Machado, 2010). Tourists' length of stay in a destination is a variable of key significance for any tourism destination due to its decisive effect on overall tourism expenditure. Length of stay in a destination determines tourists' expenditures while on a trip that add to the bread and butter for the local economy by boosting the profit to the local business. The numbers of days the tourist stayed in Sikles is depicted in the table below.

Table 4: Stay duration in Sikles

\begin{tabular}{|c|c|c|}
\hline Days & Number of Respondents & Percent (\%) \\
\hline 1 & 5 & 10.0 \\
\hline 2 & 30 & 60.0 \\
\hline 3 & 8 & 16.0 \\
\hline 4 & 5 & 10.0 \\
\hline 5 & 2 & 4.0 \\
\hline Total & 50 & 100.0 \\
\hline
\end{tabular}

Source: Field Study, 2019 
About 70 percent of tourists spent 1-2 days whereas 26 percent of them spent 3-4 days. This reveals that a large number of visitors stay in Sikles either for 1 to 2 days or for 3 to 4 days. This seems logical because those who come for travelling purpose return back home in few days. It also indicates that the length of stay is a determinant of destination demand rather than a demand characteristic largely determined by the perceived characteristics of the destination. A key factor in this respect, however, is most likely the travel distance. Since Nepal is a distant land for the western tourists, and they also plan to travel to many other tourists' destinations of Nepal, they might want to stay shorter days at a destination since they have to visit other destinations also. Taking in consideration the factors like money, time, or effort, they prefer short stay at each destination. Breaking off the holiday early and returning home is also more costly in terms of effort and monetary cost for long - distance travelers than for short-distance ones.

A study by Campo-Martinez et.al (2010) reveals that, tourist overall satisfaction had the biggest influence on the decision of whether to revisit a destination, while the least important influence was the tourist's perceived image. If the tourist finds the place interesting and gratifying they prefer to visit that place again and again. This is of vital importance in tourism management policies, because they can contribute to the better design and development of tourism promotion strategies. Most of the tourists $(94 \%)$ travelled to Sikles for the first time. Table 5 portray the number of tourists who travelled for the first time and who travelled before as well.

Table 5: Frequency of visit

\begin{tabular}{|c|c|c|}
\hline Frequency & Number of Respondents & Percent (\%) \\
\hline First time travel & 47 & 94.0 \\
\hline Travelled before & 3 & 6.0 \\
\hline Total & 50 & 100.0 \\
\hline
\end{tabular}

Source: Field Study, 2019

The tourists, who responded that they travelled Sikles before, were asked for their frequency of their previous visit to Sikles. The repeating visitors travelled Sikles onetime to 5 times which is revealed in Table 6. 
Table 6: Travelled in the past

\begin{tabular}{|l|l|c|c|c|}
\hline \multicolumn{2}{|c|}{ Frequency } & No. of Respondents & Percent & Valid Percent \\
\hline \multirow{3}{*}{ Multiple } & 1 & 1 & 2.0 & 33.3 \\
\cline { 2 - 5 } & 2 & 1 & 2.0 & 33.3 \\
\cline { 2 - 5 } & 5 & 1 & 2.0 & 33.3 \\
\cline { 2 - 5 } & Total & 3 & 6.0 & 100.0 \\
\hline First time visit & 47 & 94.0 & \\
\hline \multicolumn{2}{|l}{ Total } & 50 & 100.0 & \\
\hline
\end{tabular}

Source: Field Study, 2019

The above table depicts that only 3 tourists were repeated visitors and one of them stayed for 5 days. The repeating visitors were mainly attracted by the natural beauty of Sikles and hospitality which was unforgettable and enchanting. However, (94\%) tourists were travelling for the first time; hence it was a new experience in a new destination. Hence, it can be deduced that tourist visit frequency is a variable on the relationships among destination perceived quality and tourist satisfaction. As the motivations and drives for visiting a specific destination are very different for every tourist hence there are many aspects an individual may weigh before choosing a tourist destination. Different factors play a role in tourists' decision to visit any destination again and again viz. available infrastructure, natural and cultural diversities, local hospitality etc. Many tourists who visited Sikles feel right at home and that everyone is friendly and kind. Regardless of the location, it is always a blessing when those whom they come into contact with are genuine and kind.

\section{Information source}

Chang (2027) stated that modern tourists have a lot of travel information sources viz. internet sources, but travel magazines, television travel programs, information from friends and returnee tourist are the popular sources globally. Most of tourists were informed about Sikles by their friends, relatives and co-workers (60\%), 28 percent tourists got information from travel agency, 8 percent tourists got information from internet sources. The enchanting beauty of Sikles and local hospitality touched the hearts of tourist and hence after their return, as brand ambassador, they informed their friends and relatives to visit Sikles.

\section{Purposes of visit and tourist satisfaction}

Number of tourist by purpose of visit is a key indicator for tourism sector output. This indicator is very useful for evaluation of characteristics, type and economic and social contributions made by tourists and to plan and manage infrastructure, 
services and market economy accordingly. It also shows inflow of high value tourists (Nepal Tourism Statistics, 2019). Tourists visit new places for different seasons with different purposes. Some visit for leisure, some for rest, and for adventure, etc. The highest percent of tourists (50\%) visited Sikles for travelling purpose. They travelled for their hobby of travelling which reflects their travel for pleasure based on theory and practice of touring enchanted by natural attraction, enjoying accommodation, and entertainment. The number was followed by adventure, and relaxes purposes respectively. It also indicates that in the globalised world people want to be involved with new-fangled activities. About 28 percent tourists came to Sikles for adventure, for relaxing (18\%) and 4 percent for to get away from hectic daily life.

Tourist happiness and satisfaction is a product of the travel motivations for relationships and belonging, safety and comfort, curiosity and mental stimulation and a motive for personal development. In this process there is an important role of local peoples support. Saveriades (2001) stated that the support of the indigenous population is essential for the successful operation, further development and sustainability of tourism. When tourists are made to feel welcome by the host community, they are more likely to return as well as recommend the destination to their friends and relatives. On the other hand, however, a destination becomes less attractive if tourists are treated with indifference or disdain.

The tourist contentment is an unforgettable experience themes identified in their satisfaction. Tourist experience themes are linked to dimensions of happiness: meaning, engagement and positive emotions. For 96 percent tourists visiting Sikles, the trip was amazing, gratifying and per-expectation. They found the local scenery beautiful, landscapes breathtaking and unmatched cultural diversity. Only a single tourist was disgruntled because he experienced rude behavior from one of the hotel owners in Sikles.

\section{Tourist attraction in Sikles}

Boissevain (1977) stated that a tourist attraction is a place of interest where tourists visit, characteristically for its intrinsic or an exhibited natural or cultural value, historical significance, natural or built beauty, offering leisure and amusement. Life in Sikles is infused with indigenous Gurung tradition. Residents proudly sport cultural attire, men in white crossed bhangra vests and women in colorful lungi dresses to complete daily chores. As in most villages in Nepal, young adults are conspicuously absent, with older people and young children making up the majority of the population in Sikles. During the field observation, it was noticed that local Gurung women call from their homes to invite guests inside for a cup of tea. It was evident that tourists were welcome visitors, and their stay was cherished and appreciated. 
Table 7: Tourist attraction

\begin{tabular}{|l|c|c|}
\hline & Number of Respondents & Percent (\%) \\
\hline People and Culture & 16 & 32.0 \\
\hline Landscape and Scenery & 12 & 24.0 \\
\hline Ghalekharkha-Sikles eco route & 22 & 44.0 \\
\hline Total & 50 & 100.0 \\
\hline
\end{tabular}

Source: Field Study, 2019

Ghalekharkha-Sikles eco-route was the most attractive destination for the (44\%) tourists. Other attractions were landscape and scenery (24\%), local people and culture (32\%). Local culture and people were fascinating and were the key source of attraction for the western tourists. They found something particularly interesting that fascinated them viz. beautiful landscapes, natural beauty, magnificence and the cultural diversity and indigenous naïve traditions of generosity. For the tourist, Sikles is really a nice place and there are many appealing factors there. Mornings are to be grasped in Sikles above the village, where the white edges of Lamjung Himal $(6,983 \mathrm{~m}$.) frame golden fields and horses nibble freely in pastures. Rising Dada, an avalanche viewpoint, is about two hours by foot from the village center. Tourist are free to take pleasure in a visit to the Gurung museum to learn more about oriental Gurung culture, to the place of the honey hunters enjoying the natural surroundings, affectionate people, and their attractive customs. Broadly, tourists' general intuition on the people of Sikles was affirmative; almost all tourists responded that the local people were friendly, generous, warm-hearted, kind, polite, respectful and good host. Few tourists had the impression that people of Sikles are sturdy, disciplined, selfcontained and industrious and hence are the sources of attraction for outsiders.

The role of attractions in tourism cannot be overstated since it is common understanding that it is the attraction that draws tourists to an area without which there would be no tourism (Archer et. al 2005). It is a universal belief that attraction complete the tourism experience as they are part of accommodation, accessibility, attractions and amenities. Every destination develops and advertises their attractions to tourists as one way of emphasizing the destinations appeal. But do tourists visit a destination because of attractions, is a million dollar question. Every destination develops and sells their attractions to tourists as one way of emphasizing the destinations appeal. Tourists visit new place because that place has a particular significance. Different place are well known for different reasons. What is strength and weakness of the place and what should be done to overcome those problems, so more tourist visit the place. Most of the tourists visiting Sikles recommended to preserve the natural beauty ( 15 respondents), followed by keeping the place clean 
(12 respondents) and so on, developing infrastructure (10 respondents), developing social activities and education for local business (9 respondents), making toilets/ wash (3 respondents). Majority of tourists signaled their preference to natural beauty of Sikles. It indicates that most of tourist places of the world are modified artificially and the tourists are in search of natural beauty. Broadly this study results reveals that attractions are just some of the reasons why tourists visit Sikles. Local natural resources and social and cultural uniqueness are main source of attraction and beside that tourist come to Sikles for adventurous trekking and relaxation. If managed and well planned by the local stakeholders, it can increase the number of tourist which will definitely increase the income sources of the villagers and that will modify their life style.

\section{Visitors' intention to revisit}

Revisiting intention to tourism destinations has become a vital issue for the tactical management and marketing of destinations. Destinations are now aware of the necessity that they need attractive product features to increase tourists revisiting and recommendation to others. Tourist destination perception effects on revisit intention of tourist. There are different characteristics of the destination products that are effective in the revisit intention of the tourists (Celik et.al, 2017). For example, there is the link between destinations uniqueness, tourists' satisfaction with the quality of services offered at a destination and their intention to revisit. The influence of tourists' overall satisfaction with a destination on their behavioral intentions has been well established both at theoretical and empirical levels. About 68 percent tourists expressed their desire to return to Sikles. The reasons they presented were natural beauty, beautiful landscape, indigenous culture and pleasing hospitable behaviour of the people of Sikles. However, (16\%) respondents refused to return back to Sikles and another $(16 \%)$ were silent on this. The major pull factors of Sikles were natural beauty and beauty landscapes, and the indigenous Gurung culture and hospitality pattern.

\section{Effects of tourism in Sikles: Blessing or blight?}

It is a verity that tourism has economic dimensions. One dimension is within definition of tourism activity; that is from tourist side, tourism must not be connected to earning activity. That means, one of the main conditions of tourism activity is not doing any income activity in travelling area (Eralp, 1983). However, from economic proportions of tourism activity, tourism is an activity of financial operation which transfers money from visitors to local place. Visitors also exchange money in holiday destinations; therefore tourism is also a sort of transferring money operation financially along with the socio-cultural and environmental impacts of tourism (Escobar, 1995). Further, tourism activities take place in a natural and non-natural environment, which is extremely complex. The natural environment is 
made up of natural landscape, climate, flora and fauna present in a certain space and the non-natural environment consists of economic, social and cultural processes and factors. There can be the effects of tourists' inflow on both natural and non-natural environment. Mason (2003) argues that there can be made a clear delimitation between the two environments, which is necessary when we talk about tourism's impacts. Kunwar (1997) has identified the two broad approaches of tourism study; one aspect of the study of tourism concentrates on the political economy making the case that tourism can have a substantial and disruptive impact on the local community. Another aspect of the study of tourism is related to the anthropological reaction to the development of tourism which is dominantly negative fitting generically with the anthropological critique of modernization focusing on its cultural dimensions assessing the range of empirical effects that tourism has upon the socio-cultural and environmental system of local societies. Pedestalled on the query Sikles tourism is a blessing or blight, an assortment of positive and negative effects of tourism in the host community of Sikles has been discussed below.

\section{Economic effects of tourism}

Tourism in its nature is drawn by unique and fragile destinations, but in some cases the economic benefits can be shadowed by the negative consequences on the community and the environment, which were never estimated in the past (Dwyer et al. 2004; Archer et al. 2005). The benefits and costs generated by the tourism activity in Sikles can be viewed from two dimensions: tourists and local community. On one side there are tourists who pay to enjoy Sikles. On another side, there is the host community who enjoy the fin ancial benefits from the tourism activity. At the same time, they are the ones who have to face the hidden costs tourists leave behind. Tourism in Sikles has direct effect on economy by bringing in foreign currency. Tourism has created jobs, both through direct employment within the tourism industry and indirectly in sectors such as hotel, retail and transportation. When tourists spend their money on goods and services, it leads to multiplier effect, creating more jobs and adding to the income of local entrepreneurs. The tourism industry has provided opportunities for small-scale business enterprises in Sikles, which is especially important in rural communities. But jobs created by Sikles tourism are seasonal and poorly paid, however tourism has pushed up local property prices and the cost of goods and services. A key informant (hotel entrepreneur) reveals the situation:

Tourism in Sikles has some negative economic effects, including leakage, decline of traditional employment and seasonal unemployment. Tourism development has led to the demise of agriculture that has augmented the process of dependency on imported food items. Also, the tourism entrepreneurs face problem in keeping workers in primary industries. Seasonal unemployment is a problem in Sikles 
because tourism is not active all year round. Influx of visitors to Sikles has pushed up the price of goods and services, particularly when demand is high in peak season. This has disadvantaged poor local people who are compelled to pay higher prices for food, drinks, goods, transport, etc. Also extra charges have been levied on the local community to finance facilities and service for visitors.

Nevertheless, Sikles has boundless possibilities of promoting village tourism, as a crucial alternative economic activity of the local people with its potentiality to contribute in rural development and increasing income at the local level and to cope with financial hardships. Broadly, from an economic perspective, the objective of the host community should be to obtain higher results than the costs they have to pay, but in Sikles the local community is obligated to face many negative economic effects of tourism. Nash (1996) argues from an anthropological perspective that as because tourism as an industry impacts on people's lives, it can be classified as either fundamentally positive or negative seeing tourism as a godsend (pro-tourist) or an evil (anti-tourist). The pro-tourist position is one which is held by many planners in marginal economies who look to tourism as a new way of making money whereas the position of the anti-tourist Third World radicals who question the value of touristic development for the local people as they argue for the negative side, that economic benefits from tourism often did not trickle down to the local host community as originally believed.

\section{Socio-cultural effects of tourism}

Tourism has often been associated with the contact between cultures, behaviors, values and traditions. Tourism is considered a framework where hosts and tourists can learn better about from each other, through direct interaction. Also, tourism requires host communities to be more responsive and educated to provide quality services to tourists. In addition, interactions between locals and tourists generate the emergence of new ideas, values and motivations for social and economic progress (Brown 1998; Bersales 2005; Nyaupane et al. 2006). Mason (2003) has stated that tourism can revitalize a community's cultural life, as art and traditions are an attraction for foreign visitors. However, tourism can create diverse positive and negative socio-cultural impacts on the host community. We cannot talk about the socio-cultural impact of tourism without talking about globalization and its effects on local cultures. One result of globalization is consumerism--an increase in demand for consumption in an increasing variety of products and services. Consumerism affects tourists, who are a part of the consumer-oriented society, characterized by: modern urban lifestyle, expectations for high-level services and an attitude characterized by the expression everything is for sale (Reisinger, 2009). For Liu (2003) tourism is not the main culprit for the loss of cultural identity and traditions: the globalization and homogenization of 
culture referred to as Coca- colaisation, Hollywoodisation or Mc Donaldisation may not be caused only by tourism. The media, by means of modern communication and information technology often play a more important role in shaping the values, opinions, lifestyle and fashion of the world. Unlike this global trend there has been some positive social- cultural effect of tourism in Sikles. Tourism has urged local people of Sikles to get knowledge of foreign language especially English. Educational institutions have been opened in Sikles and more and more parents are sending their children to schools due to increasing awareness in education. Tourist inflow has affected decision making structure within households. Now gradually decision making power is shared equally by male and female in Sikles households. This is a big change towards women empowerment.

Tourism industry flourishes only when the infrastructures, tourism sites and residential area are clean and healthy. Intermingling of tourist with host has helped in augmenting awareness on health and sanitation in Sikles. Roads, houses and hotels are clean and sanitized. The behavior of people and physical resources both have changed and become conscious about good health and sanitation. The culture, customs and lifestyle of western tourists has created a direct impact on family structure of the households of Sikles. Joint family structures are gradually transforming into nuclear families. Polygamy was in practice in the previous days but due to increased education level and cultural interchange with tourists, it has dramatically decreased nowadays in Sikles.

Some studies have concluded that tourism contributes to the renaissance of traditional art and craft forms (Foster, 1964; Hartstonge, 1973; Mead, 1976; Deitch, 1977; McKean, 1977). Others have indicated that tourism has resulted in a decline in the quality of art forms and the traditional meaning of production has been debased with production for tourism consumption (Ropponen, 1976; Bascom, 1976; May, 1977). Tourism has encouraged the preservation of traditional customs, handicrafts and festivals in Sikles that might otherwise have been vanished, and it has created civic pride. Elderly Gurung people are preserving their traditional norms and practices. The local Gurung people feel pride to show the foreigners that they are rich in customs and traditions. Likewise, the interchanges between hosts and guess has created a better cultural understanding and also helped to raise global awareness of issues such as poverty, human rights abuses, women and child rights. The ambivalence of Sikles tourism is expressed in its impacts in traditional arts and crafts.

Despite few positive socio-cultural effects of tourism, there are a series of negative social-cultural effects of tourism in Sikles. Visitors' behaviors have had a detrimental effect on the quality of life of the host community. For example, crowding and congestion, drugs and alcoholism, prostitution and increased crime levels are the emerging problems observed in Sikles. With rising consumerism, tourism has 
infringed on human rights, with poor people being displaced from their land to make way for new hotels. Further, the interaction with tourists has lead to an erosion of traditional cultures and values of host community of Sikles. This small village is facing negative impacts of globalization. Local youths are abandoning traditional culture and blatantly adopting western culture especially in the matters of costume, music, song etc. Also migration to foreign countries and to urban Pokhara is a major problem Sikles is facing which is creating a condition of acute shortage of able-bodied youths in the village. An account of 65 year old local respondent (Mothers group member) during key informant interview reveals the changing trends in detail:

Many years ago when I was young, people here were so disciplined. But now many people especially youths are not disciplined. They are rude and unruly, have forgotten our traditional culture and values. This is mainly because of tourists coming here. Young boys and girls have learned bad habits such as drugs and prostitution. Many youths are involved in crimes viz. theft and vandalism. They are gradually forgetting their cultural traditions and values. Many youths are abandoning this village for foreign jobs and many families have migrated to Pokhara which is at a distance of 38 kilometers from Sikles.

Concurring to Kunwar (1997) that tourism can have a substantial and disruptive impact on the local community fitting generically with the anthropological critique of modernization focusing on its cultural dimensions of effects that tourism has upon the socio-cultural system of local societies, it is deduced that the overall sociocultural effects of tourism in the host community of Sikles has been both negative and positive.

\section{Environmental effects of tourism}

The quality of the environment, both natural and man-made, is essential to tourism. However, the relationship of tourism with the environment is complex. It involves many activities that can have adverse environmental effects. Many of these impacts are linked with the construction of general infrastructure such as roads and airports, and of tourism facilities, including resorts, hotels, restaurants, shops, golf courses etc. The negative impacts of tourism development can gradually destroy environmental resources on which it depends. On the other hand, tourism has the potential to create beneficial effects on the environment by contributing to environmental protection, conservation and in creating awareness on environment. It is a way to raise awareness of environmental values and it can serve as a tool to finance protection of natural areas and increase their economic importance (Sunlu, 2003). If the positive impact of tourism can be observed most easily on the economy, society and culture, then surely, the negative impact on the environment is the most evident. Holden (2003) has stated that compared with the economic 
impact of tourism, the environment has become a theme for studies and research recently, joining in the ecologist stream at the end of the 80s and early 90s. In Sikles, for evaluating the relationship between tourism and the environment a large number of actors involved in tourism activity needs consideration-local people, authorities (ACAP, local, provincial, central), private sector, non-governmental organizations, local community, tourists ---human as the common denominator of all these actors. While conversing on the relationship between tourism and the natural environment it is essential to deem that this relationship is the expression of human interaction with local natural environment.

Further to determine the effect of tourism on the natural environment, the vital points to be considered are the worth host community people attach to nature, cultural typecast about nature and their ethical relationship with nature. But, it is their host populace that has to pay the costs of the resulting environment degradation from tourist exploitation and the degradation is most of time observed or felt only after a period of time (Beeton, 2006). Ioannides (1995) has stated that tourism has direct negative effects on the natural environment and it puts a high pressure on the carrying capacity of host regions and indirect, from development of tourist facilities. In Sikles the correlation between tourism development and the natural environment is complex with both positive and negative effects of tourism on natural environment. The positive effects are that under the ACA project and local government authorities, Sikles tourism has helped promote conservation of wildlife and natural resources such as forests as these are now regarded as tourism assets. It has also assisted in fund generation for maintaining flora and fauna in Sikles. By creating alternative sources of employment, tourism has reduced problems of protected wildlife killing, deforestation and other environmental malpractices in Sikles. A statement by a visitor from Great Britain is presented below:

It is possible for tourism to be good for the environment sustainability. Tourism in Sikles has attempted to use the resources available whilst also conserving them for the future in sustainable environment tourism. If sustainable ecofriendly tourism can be developed in Sikles, the money generated can be used to repair and improve the natural or built environment. Tourism can also be used to educate local people and raise awareness of the importance of environmenthopefully securing their future.

The negative impacts of Sikles tourism are also multifaceted. The negative effect of tourism in Sikles poses a threat to a region's natural and cultural resources, such as water supply and heritage sites through overuse. It has caused increased garbage on trekking routes, pollution through traffic emissions, increase sewage production and noise. A statement by a visitor from United States is presented below: 
The air pollution coming from tourist transportation is one of the major negative environmental effects of tourism in Sikles. Traveling by bus, bike and road has resulted to air pollution in Sikles which has damaged the environment, also the noise; garbage and increasing land-erosion and deforestation on trekking routes owing to the extensive use of bull-dozers for road construction is another factor of negative environmental effects of increasing tourism in Sikles. Further the construction of mini-hydropower stations in the locality has deteriorated the natural environment adding to landslides and environmental degradation. But the deteriorating environment has helped in creating awareness among the host and the tourist to preserve the environment for future tourism.

In crux, though the overall socio-cultural and environmental effects of tourism in the host community of Sikles is both depressing and cheering, but there are more positive effects of tourism because it has helped in preserving local Gurung tradition and culture. It has helped in economic earning, promoting cultural understanding between guest and host and has assisted in increasing their awareness on sociocultural and environmental conservation. It has influenced decision making role within family, has helped women empowerment (as many women are involved in tourism business) and helped in reforming the marriage system. However the negative effect of tourism in Sikles is also a grave concern. Hence it is indispensable to promote socio-cultural and environmental friendly sustainable tourism in Sikles. The general experience of the tourists on Sikles tourism is positive as majority tourists' expectations were met. The tourist-host interaction is amiable that has shaped their tourism experiences in Sikles. The local natural beauty is main tourist attraction and they suggested preserving and maintaining this beauty. The landscape and breathtaking scenery and local hospitality attract tourist and compel them to recommend their friends and relatives to visit this place once with a catchphrasevisiting Sikles once is not enough.

\section{Conclusion}

In Nepal, village tourism (an innovative concept implemented as part of ecotourism) emerged as to response to the negative effect that mass tourism has had on the culture and topography of the country. Under the parasol of village tourism, the attraction resources for foreign tourists in Sikles are natural, as well as sociocultural. Tourists come to Sikles for adventure-trekking, relaxation and to take rest. Owing to a jovial relationship between the tourists and hosts, tourists' expectations were fulfilled and they were satisfied with their tourism experiences in Sikles. Further the buoyant interaction between tourist and host, experiences and discernment of the relations, along with emerging social, cultural and environmental challenges has augmented the awareness levels for both tourist and host for sustainable eco-friendly tourism. However, tourists' interaction with locals and the consequent positive and 
negative impacts on the economy, environment and social life of Sikles is a matter of grave concern. The growing number of tourists and their interactions with hosts has amplified the economic condition of the hosts but has also posed threats to local social-cultural and environmental well-being. Many local traditions and practices have come under the influence of western tourists. As a result, age-old indigenous Gurung traditions and culture has been negatively impacted especially among the youths who come into direct contact with tourists. The increased use of drugs and growth of criminal activities are also linked to tourist and host interaction.

Under the influence of tourists, the Gurung culture is facing the hitch under the process of assimilation and transformation in the name of so called westernization, modernization and consumerism. But the older generation is still reluctant to accept it but the resistance and the global forces of tourism are so strong, influencing every spheres of local life. Those forces have also influenced on the host culture as natives get chance to intermingle with the global tourists under the globalization process. But, globalization can't be termed something dissonant to traditions. It is better to find the best way between or by combining traditions and modern factors so that locals can modify them in the right way on behalf of their community. In this ground, tourism in Sikles is functioning in the right direction for the promotion and protection of Gurung culture and local setting. But positive results will depend upon how local people can create sustainable development by means of tourism without having to compromise with societal, cultural and environmental degradation. The results of this study identifies that the people of Sikles has a generally constructive attitude towards tourism and the tourists perception is also positive towards local availabilities and hospitality. Furthermore, there is some level of consensus among the local population with regards to the positive economic impacts of tourism to their area. The general conclusion that can be drawn from this study is that the changes in life-style are attributed to the changes in modern life in general, social change and their effects. At the overall level, tourism cannot be singled out as a cause of anything. In the broader sense, the key conclusion is that the changes are also brought about by modern changes in modern life.

Finally, Sikles, a village that is very rich in natural resources, unscathed cultural heritage and indigenous traditions of hospitality has a very high potentiality of developing culturally and ecologically sustainable tourism. It is certain that cultural identity and specific ecological features and uniqueness in hospitality are imperative in building a cordial guest-host relationship and for the recognition of indigenous people in a globalized world. But indigenous people face numerous challenges in a globalized world. Further, as globalization is an enduring development and inevitable, it is better to discover the best possible way ahead by acclimatizing to the global world, and as much as possible, protecting and revitalizing and conserving the 
traditional culture, indigenous pattern of hospitality and the local ecology. Because the flow of international tourists to Sikles is comparatively low at the present, the impact in entirety of tourism on the culture and ecology has been less realized till now. Hence, this study recommends that the host community and the government at the policy level should focus on the conservation of natural and cultural beauty and the tradition of unique hospitality rather than commercial earning and infrastructure development. For future research it may be interesting to do a comparative study of various tourist villages instead of only one.

\section{References}

Ahmad, S.A. (1986). Understanding resident's reaction to tourism marketing strategies. Journal of Travel Research, 25 (2), 13-18.

Archer, B., Cooper, C., Ruhanen, L. (2005). The positive and negative impacts of tourism. In Theobald, W. (Ed.) Global Tourism, Amsterdam: Elsevier.

Banskota, K \& Sharma B. (1998). Mountain Tourism for Local Community Development in Nepal. International Centre for Integrated Mountain Development, Kathmandu-Nepal.

Bascom, W. W. (1976). Changing African Art. In Graburn, N. H. H. (Ed.) Ethnic and Tourist Arts: Cultural Expressions from the Fourth World, University of California Press, Berkeley, Los Angeles, 303-319.

Beeton, S. (2006). Community Development through Tourism. Australia: Land Links.

Berger, Veit (1978). The economic impact of tourism in Nepal: an input-output analysis, $\mathrm{PhD}$ thesis, Cornell University.

Bersales, J. (2005). Contested space: tourism, power and social relations. In Alampay, R. (Ed.) Sustainable Tourism, Challenges for the Philippines, Philippines: APEC.

Boissevain, J. (1977). Tourism and Development in Malta. Development and Change, 8, 523-538.

Bowen, D., \& Schouten, A.F. (2008). Tourist satisfaction and beyond: tourist migrants in Mallorca. International Journal of Tourism Research, 10, 141-153.

Brown, O. ( 1998$)$. In search of an appropriate form of tourism for Africa: lessons from the past and suggestions for the future. Tourism Management, 19 (3), 237-245.

Bryant, B. E., and Morrison, A. J. (1980). Travel Market Segmentation and the Implementation Of Market Strategies. Journal of Travel Research, 19(3), 2-8. 
Burns, G.L. (2004). Anthropology and tourism: past contributions and future theoretical challenges. Anthropological Forum, 14 (1), 5-22. Retrieved from https://doi: 10.1080/0066467042000189908

Campo-Martínez, S, Garau-Vadel, J.B., Martínez-Ruiz, M.P. (2010). Factors influencing repeat visits to a destination: The influence of group composition Tourism Management, 31 (6), 862-870.

Can, H. \& Guner, S. (2000). Hukuku Turism. Ankara: Siyasal Kitabevi.

Celik, P., Yuzbasioglu, N, Topsakal, Y. (2017). The impact of tourists' perceptions on revisit intention. Paper presented to International Tourism Congress, 29-30 November 2017, Peniche, Portugal. Available from https://www.researchgate.net/ publication/325108383. Accessed on Aug 21, 2019.

Chang, H., Chou, C., Wu, C. (2017). Destination tourism information sources, trip quality and behavioral intention for island tourist. Retrieved from https://www. researchgate.net/publication/319159871

Cohen, E. (1979). A phenomenology of tourist experiences. Sociology, (13):2, 179201. Retrieved from https://doi.org/10.1177/003803857901300203

Cohen, E. (1996). The sociology of tourism: approaches, issues and findings. In Apostolopoulos, Y., Leivadi, S., and Yiannakis, A. (Ed.) The Sociology of Tourism: Theoretical and Empirical Investigations. London: Routledge.

De Albuquerque, K., \& McElroy, J.L. (2001). Tourism harassment: Barbados survey results. Annals of Tourism Research, 28 (2), 477-492.

Deitch, L. 1. (1977). The Impact of Tourism upon the Arts and Crafts of the Indians of the Southwestern United States. In Smith, V. L. (Ed.) Hosts and Guest: The Anthropology of Tourism, (2 $2^{\text {nd }}$ ed), University of Pennsylvania Press, Philadelphia, 173-18.

DeKadt, E. (1979). Tourism in Cyprus: Tourism: Passport to Development. Oxford University Press, New York.

Dwyer, L., Forsyth, P., Spurr, R. (2004). Evaluating tourism's economic effects: new and old approaches. Tourism Management, 25,307-317.

Eralp, Z. (1983). General Tourism, Ankara: Ankara University.

Escobar, Arturo (1995). Encountering Development: The Making and Unmaking of the Third World. Princeton: Princeton University Press.

Fanon, F. (1966). The Wretched of the Earth. Grove Press, New York.

Farell, B. H., and Runyan, D. (1991). Ecology and Tourism. Annals of Tourism Research, 18, 26-40. 
Foster, J. (1964), The Sociological Consequences of Tourism. International Journal of Comparative Sociology, 5, 217-22.

Gee, C. Y., Mackens, J. C., and Choy, D. J. (1989). The Travel Industry. Van Nostrand Reinhold, New York.

Getz, D. (1983). Capacity to absorb tourism: concepts and implications for strategic planning. Annals of tourism Research, 10, 239-263.

Goeldner, C. and Ritchie, B. (2012). Tourism, Principles, Practices, Philosophies. New Jersey: John Wiley and Sons.

Graefe, A.R., \& Vaske, J.J. (1987). A framework for managing quality in the tourist experience. Annals of Tourism Research, 14, 390-404.

Greenwood, D. J. (1989). Culture by the Pound: An Anthropological Perspective on Tourism and Cultural Commoditisation. In Smith, V. L. (Ed.) Hosts and Guest: The Anthropology of Tourism, (2 ${ }^{\text {nd }}$ ed), University of Pennsylvania Press, Philadelphia, 171-185.

Gunn, C. A. (1988). Tourism Planning. Taylor and Francis, New York.

Hartstonge, J. E. (1973). Arts and Crafts. Proceedings of the Pacific Area Travel Association Workshop, Kyoto, Japan, 217-219.

Hester, R. T. (1990). The sacred structure of small towns: return to Manteo, North Caronina. Small Town, 20 (4), 4-21.

Holden, A. (2003). In need of new environmental ethics for tourism? Annals of Tourism Research, 30 (1), 94-108.

Holloway, C. J. (1988). The Business of Tourism. London: Pitman Publishing.

Ioannides, D. (1995). A flawed implementation of sustainable tourism, the experience of Akamas, Cyprus. Tourism Management, 16 (8), 583-592.

Jonsson Kvist, A.K., \& Klefsjo, B. (2006). Which service quality dimensions are important in inbound tourism? A case study in a peripheral location. Managing Service Quality, 16 (5), 520-537.

Knox, John M. (2004). Sustainable tourism in Hawaii: Socio-cultural and public input component. Summary report prepared for the Project: Planning for Sustainable Tourism in Hawaii, Hawaii State Department of Business, Economic Development \& Tourism. Honolulu, Hawaii. Retrieved March 5, 2005, from http://www. hawaiitourismstudy.com

Kousis, M. (1989). Tourism and the Family in a Rural Cretan Community. Annals of Tourism Research, 16, 318-333.

Kozak, M. (2007). Tourism harassment: a marketing perspective. Annals of Tourism Research, 34 (2), 384-399. 
Kunwar, R.R. (1997). Tourism and Development: Science and Industry Interface. Kathmandu: Laxmi Kunwar.

Liu, Z. ( 20003$)$. Sustainable tourism development: a critique. Journal of Sustainable Tourism, 11 (6), 459-475.

Machado, L.P. (2010). Does Destination Image Influence the Length of Stay in a Tourism Destination? Retrieved from https://doi.org/10.5367/000000010791305554

Mason, Peter (2003). Tourism Impacts, Planning and Management. Amsterdam: Butterworth Heinemann.

May, R. J. (1977). Tourism and the Artefact in Papua New Guinea. In Finney, B. R., and Watson, (Ed.) A New Kind of Sugar: Tourism in the Pacific, Centre for South Pacific Studies, University of California, Santa Cruz, 125-133.

McIntosh, R., and Goeldner, C. (1990). Tourism: Principles, Practices and Philosophies. Wiley, New York.

McKean, P. F. (1977). From Purity to Pollution? A Symbolic Form in Transition: The Balinese Ketjak. In Becker, A., and Yengoyen, A. (Ed.) The World Imagination of Reality: Symbol Systems in South-East Asia, University of Arizona Press, Tucson, 293-302.

McNicoll, 1. H. (1979). The Shetland Economy An Empirical Study in Regional InputOutput Analysis (Research Monograph No. 2). The Frazer of Alliance Institute, University of Strathclyde.

Mead, S. M. (1976). The Production of Native Art and Craft Objects in Contemporary New Zealand Society. In Graburn, N. H. H. (Ed.) Ethnic and Tourist Arts: Cultural Expressions from the Fourth World, Berkeley and Los Angeles, University of California Press, 285-298.

Mill, R.C. and Morrison, A.M. (1985). The Tourism System: An Introductory Text. New Jersey: Prentice-Hall.

Murphy, P. E. (1985). Tourism: A Community Approach. Routledge, London.

Murphy, P., Pritchard, M.P., \& Smith, B. (2000). The destination product and its impact on traveller perceptions. Tourism Management, 21, 43-52.

Nash, D. (1996). Anthropology of Tourism. Pergamon: New York.

Nepal Tourism Statistics (2019). Fact Sheet. Ministry of Culture, Tourism and Civil Aviation, Singha Durbar, Kathmandu.

Nyaupane, G. P., Morais, D. B. and Dowler, L. (2006). The role of community involvement and number/type of visitors on tourism impacts: A controlled comparison of Annapurna, Nepal and Northwest Yunnan, Nepal. Tourism Management, 27, 1373-1385. 
Peppelenbosch, P., and Templeman, G. (1989). The Pros and Cons of International Tourism to the Third World. In Singh, T., Theuns, V. L., and Go, F. M. (Ed.) Frandfurtam, PeterLang, Main.

Pizam, A., Neumann, Y., \& Reichel, A. (1978). Dimentions of tourist satisfaction with a destination area. Annals of Tourism Research, 5 (3), 314-322.

Reisinger, Yvette (2009). International Tourism, Cultures and Behavior. Oxford: Butterworth- Heinemann.

Ropponen, P. J. (1976). Tourism and the Local Population. In Economic Commission for Europe, Planning and Development of the Tourist Industry in the E. C. E. Region, United Nations, New York.

Saveriades, Alexis (2001). A Qualitative Examination of Perceptions of the Impact of Tourism Upon Family Life in Cyprus. A PhD dissertation submitted to the University Of Surrey School Of Management Studies in part-fulfillment of the requirements for the award of the Degree of $\mathrm{PhD}$. for the Service Sector.

Sjoberg G, Nett R. (1968). A Methodology for Social Research. New York: Harper and Row.

Sunlu U. (2003). Environmental impacts of tourism. In Camarda D. \& Grassini L. (Ed.) Local resources and global trades: Environments and agriculture in the Mediterranean region. Bari: CIHEAM, 263-270. http://om.ciheam.org/article. php?IDPDF=4001977

Thyne, M., Lawson, R., \& Todd, S. (2006). The use of conjoint analysis to assess the impacts of the cross-cultural exchange between hosts and guests. Tourism Management, 27, 201-213.

Uysal, M., Pomeroy, R. S., and Potts, T. D. (1992). County-level tourism impact assessment: a case study in Beaufort county, South Carolina. Journal of Travel Research, 31(1), 57-65.

Weiermair, K. (2000). Tourists' perceptions towards and satisfactions with service quality in the cross-cultural service encounter: implications for hospitality and tourism management. Managing Service Quality, 10 (6), 397-409.

Witt, S. F. (1991). Tourism in Cyprus: balancing the benefits and costs. Tourism Management, 12(1), 37-46.

Young, R. C. (1977). The structural context of the Caribbean tourist industry: A comparative study. Economic Development and Cultural Change, 25(4), 657-67. 